\title{
The microRNA 132 Regulates Fluid Shear Stress-Induced Differentiation in Periodontal Ligament Cells through mTOR Signaling Pathway
}

Lin Qi Yang Zhang

Department of Orthodontics, School of Stomatology, China Medical University; Shenyang City, P. R. China

Key Words

$\mathrm{PDL} \cdot \mathrm{FSS} \cdot$ microRNA $\bullet$ differentiation $\bullet \mathrm{mTOR}$ signaling pathway

\begin{abstract}
Background/Aims: Once tissue destruction has occurred, the differentiation of periodontal ligament (PDL) cells into osteoblasts plays an important role in repairing the oral cavity. Methods: In this work, we measured the proliferation and differentiation of PDL cells after fluid shear stress (FSS) treatment by ALP activity assays and in vitro mineralization assays respectively. The levels of miRNA in PDL cells treated with FSS or not were detected by using microRNA arrays. The possible signaling pathway was determined by western-blot. Results: This study demonstrates that FSS modulates several functions of human PDL cells. Specifically, increasing FSS in fixed increments regulates the proliferation and differentiation of PDL cells. Through microRNA arrays, we find that FSS induced-differentiation is accompanied by a significantly higher level of miR-132 compared to untreated controls. Phosphorylated levels of the P13K, AKT, mTOR, and p70S6K proteins also significantly increases in FSS-treated PDL cells. Finally, the FSS-induced differentiation of PDL cells is inhibited by miR-132 knockdown probe and the mTOR signaling pathway inhibitor BEZ235. Conclusion: Our data support the hypothesis that FSS-induced differentiation and proliferation involves the PI3K/AKT/mTOR signaling axis, through a process involving mir-132.
\end{abstract}


Qi/Zhang: The Role of mir-132 and FSS in the Differentiation of PDL

\section{Introduction}

A tooth is supported by periodontium, of which periodontal ligament (PDL) is the main constituent. PDL cells are a heterogeneous population that can differentiate into fibroblasts, cementoblasts, and osteoblasts $[1,2]$. Once tissue destruction has occurred, one of the major goals of periodontal treatment is to regenerate the affected tissue.

Previous studies have demonstrated the importance of PDL in periodontal regeneration $[3,4]$. For example, PDL cell differentiation into osteoblasts is important in bone formation. There is some evidence that PDL cells can differentiate into osteoblasts or cementoblasts, and are therefore implicated in the regeneration of alveolar bone and cementum as well as PDL $[5,6]$. Many studies have reported that PDL cells can form mineralized nodules, both in vitro and in vivo $[7,8]$. Fluid shear stress (FSS) plays an important role in modulating the functions of many types of cells, such as osteocytes [9], endothelial cells [10], and bone marrow stromal cells [11]. Interstitial fluid is squeezed out of the space around the PDL cells and generates fluid shear stress on the PDL cells. van der Pauw et al. [12] reported that FSS significantly elevated release of nitric oxide. Maeda et al. [13] demonstrated that FSS increased IL-8 mRNA expression in PDL cells but decreased MIP-1a mRNA expression. Yet the question of whether FSS promotes PDL differentiation directly has not been addressed, and the molecular pathways by which this occurs are unknown.

Recently, post-transcriptional regulators of gene expression have gained attention. MicroRNAs (miRNAs) are small (19-25 nucleotides), noncoding RNAs that interact with complementary or near complementary target sites in the untranslated region (UTR) of target gene sequences. miRNAs play important roles in the post-transcriptional regulation of target genes by directing target mRNAs for translational repression or destabilization [14]. Previous studies have demonstrated that miRNAs are involved in biological processes such as cell proliferation, cell differentiation, and apoptosis [15]. The role of miRNAs in PDL differentiation has never been addressed. Given the role of miRNAs in regulating differentiation and proliferation of other cell types, we hypothesize that miRNAs may play a role in the FSS-induced differentiation of human PDL cells. To evaluate this possibility, we examined over 200 miRNAs in human PDL cells treated with fluid shear stress, and compared the measurements to untreated controls. The results of our study suggest that fluid shear stress can induce PDL cells to mature, a process that is essential for regeneration of the PDL ligament.

We find that elevated levels of miR-132 accompany the FSS-induced differentiation of human PDL cells. Previous studies have demonstrated the central roles of miR-132 in several important processes: dendritic branching and spine formation in neurons, angiogenesis during tumor growth, the regulation of immunity, and viral replication [16, 17]. FSS-induced differentiation in human PDL cells was inhibited by miR-132 knockdown probe. A PI3K/AKT and mTOR signaling pathway inhibitor, BEZ235, also blocked FSS-induced differentiation in human PDL cells. Our data support the hypothesis that FSS-induced differentiation and proliferation involves the PI3K/AKT/mTOR signaling axis, through a process involving mir132.

\section{Materials and Methods}

\section{Culture of PDL Cells and Immortalization}

hPDL cells were isolated using an explant culture technique, from patients with ages under 25 years undergoing orthodontic treatment. The precise method is described in reference [18]. This study is in compliance with the Helsinki Declaration and approved by the Ethical Committee of China Medical University. PDL tissue was removed from the extracted teeth after patients provided their written informed consent. In all cases where minors/children participated in our study, their caretakers signed the informed consent. To immortalize the PDL cells, we used pBABE-puro-hTERT plasmid (kindly provided by Li Yan, China Medical University) to generate retrovirus carrying the human telomerase reverse-transcriptase gene (hTERT) [19]. The immortalized PDL cells are designated I-PDL cells. 


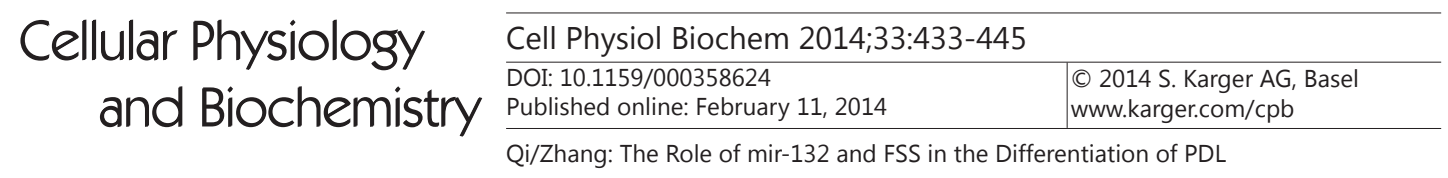

Fluid flow experiments

Fluid flow was applied to cells in a parallel plate flow chamber using a closed loop, as described previously [20]. This system uses a constant hydrostatic pressure head to drive media through the channel of the flow chamber, in order to subject the cell monolayer to steady laminar flow resulting in a well-defined fluid shear stress $\left(3,6,9,12\right.$, and 15 dynes $\left./ \mathrm{cm}^{2}\right)$. The apparatus was maintained at $37^{\circ} \mathrm{C}$ throughout the duration of the experiment.

\section{[3H] Thymidine incorporation assays}

Cell proliferation was assessed by monitoring incorporation of [methyl- ${ }^{3} \mathrm{H}$ ] thymidine (Sigma-Aldrich, Carlsbad, CA, USA). Briefly, the cells were seeded into each well of a 96-well assay plate, with 1500 cells per well. This experiment was repeated four times. After $2 \mathrm{~d}$, the cells were incubated with $20 \mathrm{mCi} /$ well [methyl- ${ }^{3} \mathrm{H}$ ] thymidine for $16 \mathrm{~h}$. The cells were then washed with ice-cold $\left(0^{\circ} \mathrm{C}\right) \mathrm{PBS}$ and lysed with ice-cold $10 \%$ trichloroacetic acid (TCA) in PBS for $20 \mathrm{~min}$ at $4^{\circ} \mathrm{C}$. Ice-cold $0.2 \mathrm{M} \mathrm{NaOH}$ was then added to the cells, and after $10 \mathrm{~min}$ at $-20^{\circ} \mathrm{C}$, we collected cell lysates and added universol scintillation cocktail (2.5 ml). The incorporation of [methyl ${ }^{3} \mathrm{H}$ ] thymidine into DNA was assessed using a liquid scintillation counter (Xi'an Nuclear Instrument Factory, Xi'an, China), and measured as disintegrations per minute (dpm).

\section{Determination of cell number by crystal violet staining}

PDL cells $\left(3 \times 10^{3} / \mathrm{cm}^{2}\right)$ were seeded in 12 -well plates with osteogenic induction media. This experiment was repeated three times. The media were changed every $3 \mathrm{~d}$. Two weeks later, the cells were fixed with ice-cold methanol for $10 \mathrm{~min}$. After PBS washing, $0.5 \%$ crystal violet solution was added for 10 $\mathrm{min}$. The crystal violet was removed and the plates were washed carefully with water 3 times. Photographs were taken using a Nikon digital camera. For crystal violet quantification, Sorenson's buffer ( $0.1 \mathrm{M}$ sodium citrate, $50 \%$ ethanol, $50 \% \mathrm{H}_{2} \mathrm{O}$ ) was used to extract the dye, and the color of the cells was then measured using a spectrometer (Beckman Coulter, Mason, MI, USA) at $540 \mathrm{~nm}$. The optical density readout is positively correlated with cell number.

\section{In vitro mineralization assay}

PDL cells were seeded in 6-well plates in triplicate at the density of $3 \times 10^{3} / \mathrm{cm}^{2}$. Alizarin Red S staining, which detects calcium deposition, was used as an indicator of mineralization. The cells were rinsed in PBS, and fixed in 70\% ice-cold ethanol prior to staining with $40 \mathrm{mM}$ Alizarin Red S ( $\mathrm{pH}=4.2$, Sigma) for $10 \mathrm{~min}$ at room temperature. Calcium content was quantified by measuring the amount of Alizarin Red $\mathrm{S}$ staining, which was bound to the mineralizing nodules. Alkaline phosphatase (ALP) staining was performed as previously described [21].

\section{RNA isolation}

Total cellular RNA was extracted using the mirVana miRNA Isolation kit (Ambion, Austin, TX, USA), following the manufacturer's instructions for total RNA isolation. The RNA concentration was determined by spectrophotometric absorbance at $260 \mathrm{~nm}$, and the quality of the RNA was determined using the Agilent 2100 Bioanlayzer instrument (Agilent Technologies, Santa Clara, CA, USA). All RNA samples showed high quality (RNA integrity number (RIN) > 9.0) and were without RNA degradation or DNA contamination.

\section{miRNA Microarray}

Microarray analysis was performed with the Agilent Whole Human Genome Array, following the manufacturer's instructions. In brief, $5 \mu \mathrm{g}$ of total fluorescent labeled RNA were analyzed in duplicate by two-sample (dual color) competitive hybridization, with a dye swap to control for labeling efficiency. For the reference channel the total RNA from samples were pooled in equal quantities. Data were acquired using the Agilent G2565BA Microarray Scanner System and Agilent Feature Extraction Software (v9.1). Probe intensities were normalized using GeneSpring GX 11.0. The Agilent Feature Extraction software [22] depicted 55 miRNA probes that were detected on at least one out of four arrays with significant signal-toerror ratio. Intensity values for each individual time point were adjusted by setting negative values to " 1 ". Each individual intensity measurement is normalized with respect to the corresponding intensity value of the control group. We generated a heat map for the 55 detectable probes based on hierarchical clustering of their mean-centered intensities, using a Euclidean distance measure. This analysis was performed using the open source software Cluster/Tree view. 


\begin{tabular}{|c|c|c|}
\hline Cellular Physiology & Cell Physiol Biochem 2014;33:433-445 & \\
\hline and Biochemistry & 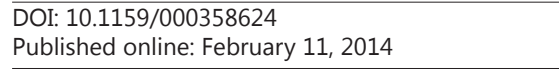 & $\begin{array}{l}\text { (0 2014 S. Karger AG, Basel } \\
\text { www.karger.com/cpb }\end{array}$ \\
\hline
\end{tabular}

Transfection

We obtained the miR-132 knockdown probe CGACCATGGCTGTAGACTGTTA and the scramblemiR-132 control GTGTAACACGTCTATACGCCCA from GenePharma (Shanghai, China). We also obtained miR-132 mimics and mimics their negative controls as a gift from Dr. Lin Jie (China Medical University). For transfections, cells were plated at $70-80 \%$ confluency in a 6-well dish. The following day, cells were transfected with $1 \mu \mathrm{g}$ of the chemically synthesized RNA using Lipofectamine 2000 (Invitrogen, Carlsbad, CA, USA) according to the manufacturer's protocol.

Pharmacologic agents

BEZ235, a dual PI3K/mTOR inhibitor described previously [23], was a generous gift from Novartis Pharma AG (Basel, Switzerland). The BEZ235 (10 $\mathrm{mM})$ was dissolved in DMSO (Sigma) and stored at $-20^{\circ} \mathrm{C}$ until the experiments. Insulin like-growth factor I (IGF-1), an activator of the mTOR signaling pathway [24], was a gift from Miss Wang Rong (China Medical University).
Table 1. Primers used in Real-time PCR analyses

\begin{tabular}{ll}
\hline Gene & Sequence (5'-3'; Forward/Reverse) \\
\hline Pre-miR-132 & CCGCGTCTCCAGGGCAAC \\
& CCTCCGGTTCCCACAGTAACAA \\
ALP & GCACCTGCCTTACTAACTCC \\
& CATGATCACGTCAATGTCC \\
OCN & CTCACACTCCTCGCCCTATT \\
& CTCCAGCCATTGATACAGCT \\
PON & CAGTGACCAGTTCATCAGATTCATC \\
& CACACTCTTTGCTCCCACC \\
& GAATCGCACCGTTTCTCC \\
\hline
\end{tabular}

Reverse Transcription Quantitative PCR

To quantify the mature form of miR-132, we performed reverse transcription of 10 ng RNA using a TaqMan MicroRNA Reverse Transcription kit (Applied Biosystems). This step was followed by a TaqMan miRNA assay (Applied Biosystems) using primers and probes specific for miR-132 or for the U6 RNA internal control, according to the manufacturer's protocol. The mRNA expressions of ALP, OCN, OPN, and $P O N$ used the primers presented in Table 1. Amplification was conducted in an ABI Prism 7500 Real-time PCR System. The PCR conditions were as follows: $95^{\circ} \mathrm{C}$ for $10 \mathrm{~min}, 40$ cycles at $95^{\circ} \mathrm{C}$ for $15 \mathrm{sec}$, $60^{\circ} \mathrm{C}$ for $1 \mathrm{~min}$. The $\Delta \Delta \mathrm{Ct}$ method was used to analyze estimates of the mature form of miR-132 in triplicate samples.

\section{Immunoblot analysis}

Cells subjected to static and oscillatory fluid flow were harvested in an SDS sample buffer, and protein concentrations were determined using the amino black method. Protein extracts (45 $\mu \mathrm{g}$ ) were separated by SDS/PAGE and transferred to NC membranes. Membranes were blocked with 5\% (w/v) nonfat milk in PBST, then probed with several primary antibodies at $4{ }^{\circ} \mathrm{C}$ overnight. We used the following primary antibodies: ALP (ab95462, Abcam, Hong Kong, China), OPN (ab8448, Abcam), OCN (sc-376726, Santa Cruz Biotechnology, Santa Cruz, CA), PON (sc-49480, Santa Cruz), phospho-PI3K (4228, Cell signaling technology, Danvers, MA, USA), PI3K (4249, Cell signaling), phospho-Akt1 (2965, Cell signaling), Akt1 (9272, Cell signaling), phospho-mTOR (2971, Cell signaling), mTOR (4517, Cell signaling), phopho-p70S6K (9206, Cell signaling), p70S6K (2708, Cell signaling), and $\beta$-actin (sc-47778, Santa Cruz). The membranes were washed, then incubated with the appropriate secondary antibodies for $2 \mathrm{~h}$ at room temperature. Finally, bound antibodies were detected using an enhanced chemiluminescence kit (Amersham Biosciences, Westborough, MA, USA) according to the manufacturer's directions.

\section{Statistical Analysis}

All measurements of the FSS groups are compared to the unsheared controls using Student's $t$-test (two-tailed) for paired samples (GraphPad 5.0). Statistical significance was set to a $p$-value less than 0.05. Each experiment was repeated three times. 
Fig. 1. Fluid shear stress regulates osteogenic differentiation in PDL cells. A) Cell proliferation following each stage of the FSS treatment was assessed by [methyl${ }^{3} \mathrm{H}$ ] thymidine incorporation assays. B) ALP activity was measured by ALP staining and quantified assay. Mineralization was assessed by Alizarin Red staining, which quantifies the extracellular calcium concentration.

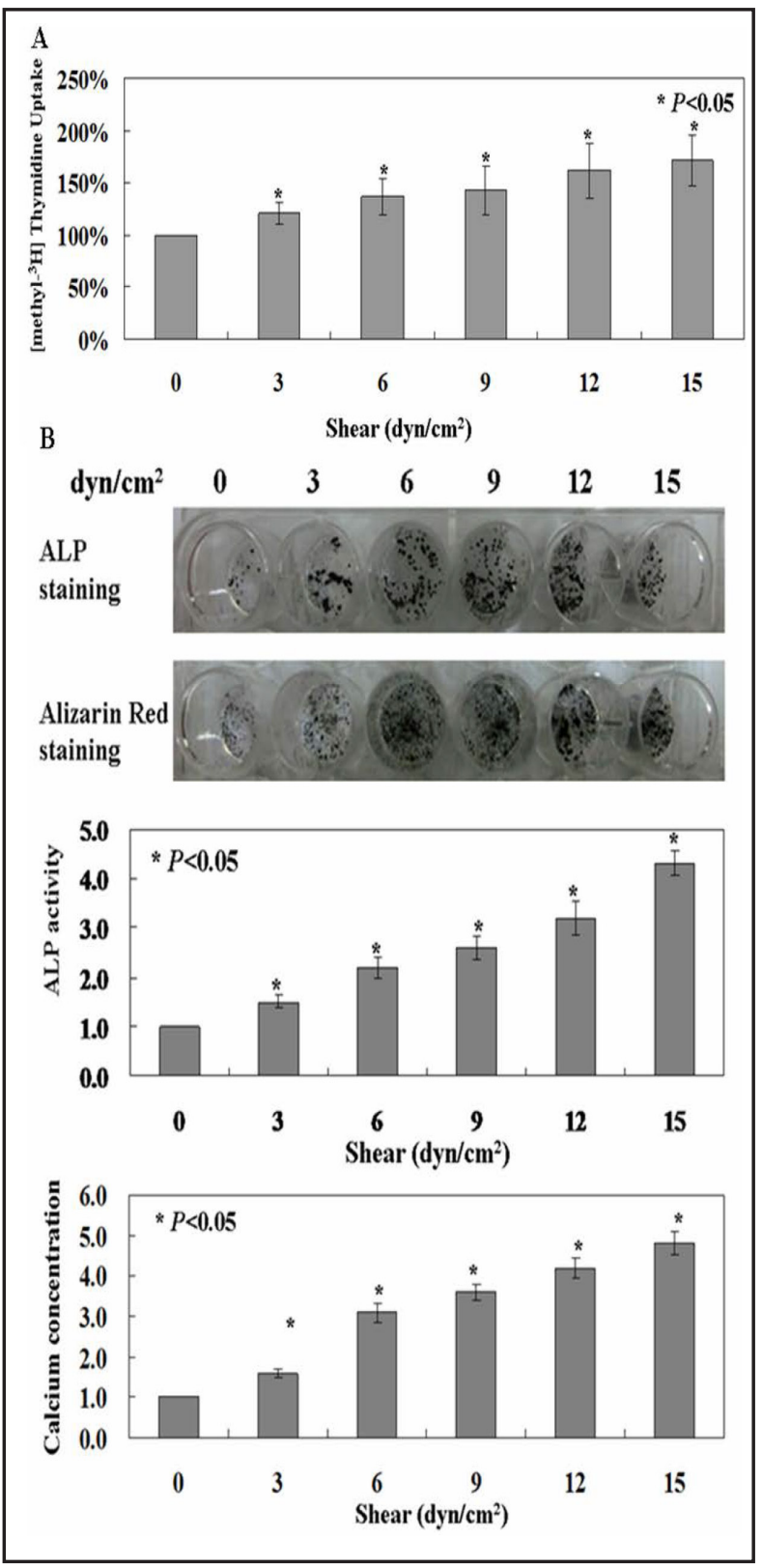

\section{Results}

The proliferation and differentiation of I-PDL cells are regulated by FSS

The expression of alkaline phosphatase (ALP), osteocalcin (OCN), osteopontin (OPN), and periostin (PON) profoundly affect the differentiation of PDL cells [25-27]. Compared to a control group with no FSS, we found that increasing FSS in fixed increments (3-6-9-12-15 dyn $/ \mathrm{cm}^{2}$ ) over a 6-hour period significantly increased the proliferation rate of immortalized PDL (I-PDL) cells by $50 \%$ (Fig. $1 \mathrm{~A}$ ) relative to the control group $\left(0 \mathrm{dyn} / \mathrm{cm}^{2}\right)$. Between the first and last FSS steps, osteoblastic ALP activities and calcium deposition rates increased from $1.5 \pm 0.14$ times to $5.5 \pm 0.26$ times with respect to the control group (Fig. 1B). To confirm the osteogenic potential of this cell line, we treated I-PDL cells with increasing levels of FSS as indicated above. The mRNA levels of the genes $A L P, O C N, O P N$, and $P O N$ were found to be up-regulated (Fig. 2A). This treatment also increased ALP, OPN, OCN, and PON protein expression (Fig. 2B). 
Fig. 2. The differentiation markers of PDL cells before and after the FSS treatment. A) The mRNA levels of miR-132, ALP, OPN, OCN, and PON were determined by real-time PCR. B) The expressions of ALP, OPN, OCN, and PON were determined by Western blot, in PDL cells treated with stepwise increasing levels of FSS (3-6-9-12-15 dyn/cm2). $\beta$-actin expression was used as an internal control.

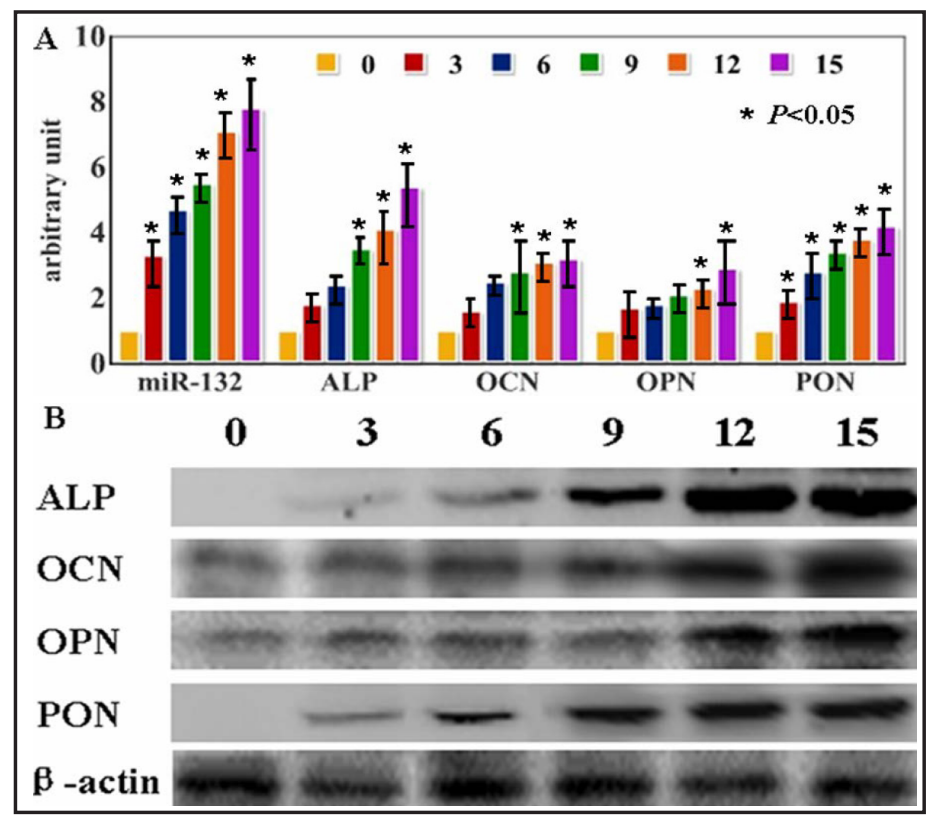

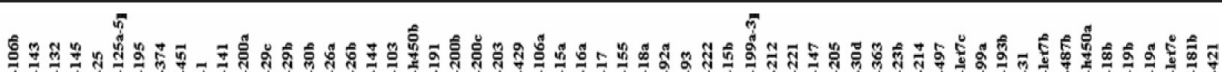

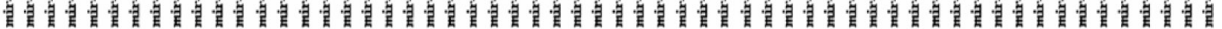

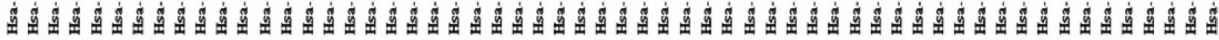
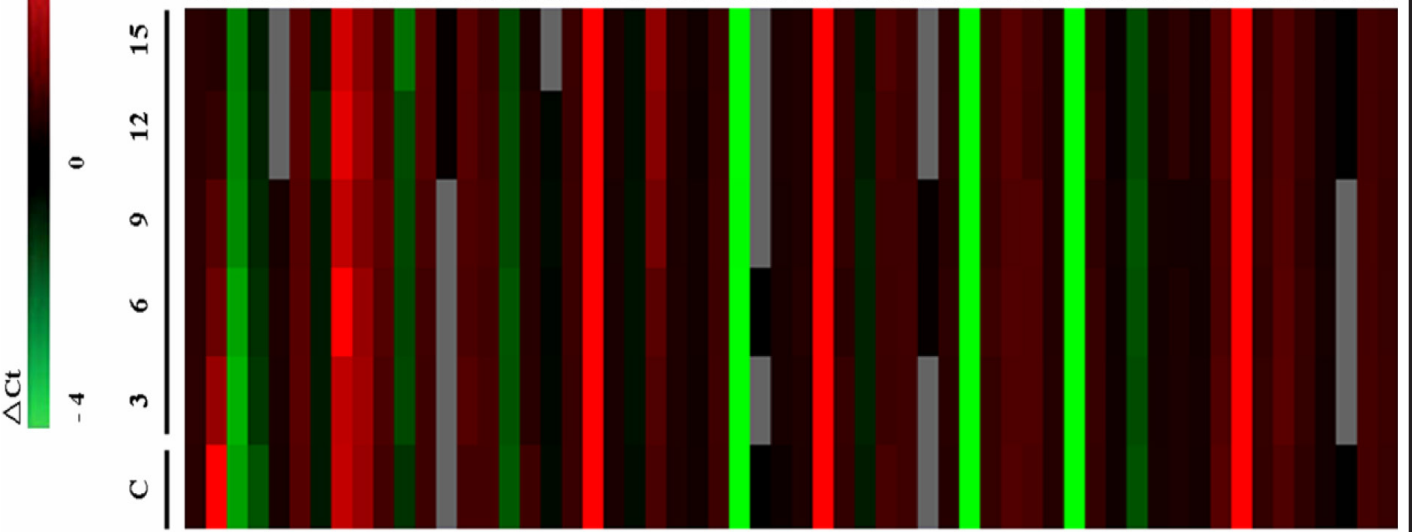

Fig. 3. Microarray analysis identified many subtle differences in miRNA expressions during the stepwise increasing FSS (3-6-9-12-15 dyn/ $\mathrm{cm}^{2}$ ) treatment. The intensities are mean centered, with red indicating higher values and green indicating lower values.

FSS treatment up-regulates miRNA-132 in I-PDL cells

To search for miRNAs that may be involved in the differentiation of I-PDL cells, we used array analysis to screen for miRNAs that are differentially expressed between all sheared groups and the control group (Fig. 3). We found changes in the expression of many miRNAs in I-PDL cells after FSS treatment. In particular, the expression of miR-132 was three times higher in all sheared groups compared with the controls (Table 2). Real-time PCR analysis confirmed that miR-132 is significantly increased in all sheared groups compared with static controls (Fig. 2A).

Knocking down miRNA-132 can inhibit the FSS-induced proliferation and differentiation of I-PDL cells

Next, we explored the function of miR-132 in FSS-induced proliferation and differentiation of I-PDL cells by knocking down miRNA-132. The proliferation assay showed that miR-132 knockdown significantly repressed the FSS-induced proliferation rate of I-PDL cells (Fig. 
Qi/Zhang: The Role of mir-132 and FSS in the Differentiation of PDL

4A). Other assays were consistent with this result, demonstrating that miR-132 knockdown inhibits both ALP activity and in vitro calcium deposition (Fig. 4B). Furthermore, an analysis of differentiation markers in the knocked down I-PDL cells (Fig. 5, lane 3) measured a modest decrease in ALP protein, and a remarkable decrease in the OPN, OCN, and PON proteins compared to cells with FSS but without the miR-132 knockdown (Fig. 5, lane 2). However, a scrambled miR132 oligonucleotide had no effects on the proliferation ratio, ALP activity, calcium deposition (Fig. 4) or differentiation markers (Fig. 5, lane 4) of I-PDL cells with FSS treatment.

Suppression of mir-132 blocks $P D L$ cell differentiation and activation of the mTOR signaling pathway

To confirm activation of the mTOR signaling pathway following FSS treatment in PDL cells, we performed a Western blot analysis using antibodies that recognize phosphorylated, active proteins of the pathway. This analysis showed that phosphorylated levels of the P13K, AKT, mTOR, and p70S6K proteins were significantly greater in FSS-treated cells (Fig. 6, lane 2)
Table 2. Summary of significant differentially expressed miRNAs in PDL cells. * sheared groups versus unsheared controls

\begin{tabular}{|c|c|c|c|c|c|}
\hline \multicolumn{3}{|c|}{ Upregulated miRNAs } & \multicolumn{3}{|c|}{ Downregulated miRNAs } \\
\hline miRNA ID & Fold change* & $P$ value & miRNA ID & Fold change* & P valu \\
\hline \multicolumn{6}{|l|}{3 dynes $/ \mathrm{cm}^{2}$} \\
\hline Hsa-mir-132 & 3.315 & 0.024 & Hsa-mir-25 & 0.805 & 0.063 \\
\hline Hsa-mir-200a & 1.181 & 0.059 & Hsa-mir-29c & 0.993 & 0.049 \\
\hline \multirow[t]{3}{*}{ Hsa-mir-144 } & 1.186 & 0.054 & Hsa-mir-203 & 0.947 & 0.045 \\
\hline & & & Hsa-mir-26b & 0.956 & 0.047 \\
\hline & & & Hsa-mir- 155 & 0.933 & 0.048 \\
\hline \multicolumn{6}{|l|}{6 dynes $/ \mathrm{cm}^{2}$} \\
\hline Hsa-mir-132 & 4.705 & 0.028 & Hsa-mir-25 & 0.756 & 0.056 \\
\hline Hsa-mir-200a & 1.143 & 0.049 & Hsa-mir-29c & 0.980 & 0.041 \\
\hline \multirow[t]{3}{*}{ Hsa-mir-144 } & 1.191 & 0.051 & Hsa-mir-203 & 0.889 & 0.042 \\
\hline & & & Hsa-mir-26b & 0.972 & 0.045 \\
\hline & & & Hsa-mir-155 & 0.932 & 0.047 \\
\hline \multicolumn{6}{|l|}{9 dynes $/ \mathrm{cm}^{2}$} \\
\hline Hsa-mir-132 & 5.487 & 0.037 & Hsa-mir-25 & 0.713 & 0.043 \\
\hline Hsa-mir-200a & 1.168 & 0.054 & Hsa-mir-29c & 0.914 & 0.059 \\
\hline \multirow[t]{3}{*}{ Hsa-mir-144 } & 1.196 & 0.069 & Hsa-mir-203 & 0.717 & 0.889 \\
\hline & & & Hsa-mir-26b & 0.903 & 1.000 \\
\hline & & & Hsa-mir-155 & 0.917 & 0.208 \\
\hline \multicolumn{6}{|l|}{12 dynes $/ \mathrm{cm}^{2}$} \\
\hline Hsa-mir-132 & 7.052 & 0.026 & Hsa-mir-25 & 0.673 & 0.037 \\
\hline Hsa-mir-200a & 1.207 & 0.061 & Hsa-mir-29c & 0.819 & 0.057 \\
\hline \multirow[t]{3}{*}{ Hsa-mir-144 } & 1.201 & 0.057 & Hsa-mir-203 & 0.624 & 0.889 \\
\hline & & & Hsa-mir-26b & 0.901 & 1.000 \\
\hline & & & Hsa-mir- 155 & 0.905 & 0.039 \\
\hline \multicolumn{6}{|l|}{15 dynes $/ \mathrm{cm}^{2}$} \\
\hline Hsa-mir-132 & 7.848 & 0.019 & Hsa-mir-25 & 0.644 & 0.034 \\
\hline Hsa-mir-200a & 1.597 & 0.889 & Hsa-mir-29c & 0.813 & 0.044 \\
\hline \multirow[t]{3}{*}{ Hsa-mir-144 } & 1.286 & 0.779 & Hsa-mir-203 & 0.583 & 0.037 \\
\hline & & & Hsa-mir-26b & 0.879 & 0.045 \\
\hline & & & Hsa-mir-155 & 0.905 & 0.028 \\
\hline
\end{tabular}
compared with untreated cells (Fig. 6, lane 1). The total protein levels of P13K, AKT, mTOR, and p70S6K in the treated cells remained unchanged (Fig. 6, lane 1 \& lane 2). Phosphorylated levels of P13K, AKT, mTOR, and p70S6K proteins were inhibited by miR-132 knockdown probe (Fig. 6, lane 3) compared to the treated cells (Fig. 6, lane 2). To evaluate the role of the mTOR signaling in FSS-induced differentiation, both the cells treated with FSS and the untreated cells were exposed to BEZ235, an inhibitor of the pathway. This experiment significantly reduced the phosphorylated levels of P13K, AKT, mTOR, and p70S6K proteins compared to the unsheared controls (Fig. 6, lane5).

Up-regulation of mir-132 induces PDL cell differentiation and activation of the mTOR signaling pathway

To confirm the role of the mTOR signaling pathway in PDL cells, we activate this pathway using IGF-1. The results of the proliferation assay, ALP activity, and in vitro calcium deposition show that activation of the mTOR signaling pathway significantly enhances the proliferation rate of I-PDL cells (Fig. 7). Furthermore, we up-regulated mir-132 using mir132 mimics. The results show that up-regulation of mir-132 can activate the mTOR signaling pathway (Fig. 8), and subsequently induce PDL cell differentiation (Fig. 7). 
Fig. 4. microRNA 132 regulates FSS-induced osteogenic differentiation in PDL cells. A) Cell proliferation was assessed by [methyl$\left.{ }^{3} \mathrm{H}\right]$ thymidine incorporation assays. B) ALP activity and mineralization were measured by ALP staining and Alizarin Red staining, respectively. Normal: PDL cells; FSS: PDL cells treated with FSS; FSS+ knockdown probe: PDL cells treated with FSS and knockdown probe; FSS+scramble: PDL cells treated with FSS and scrambled RNA; FSS+BEZ235: PDL cells treated with FSS and BEZ235.

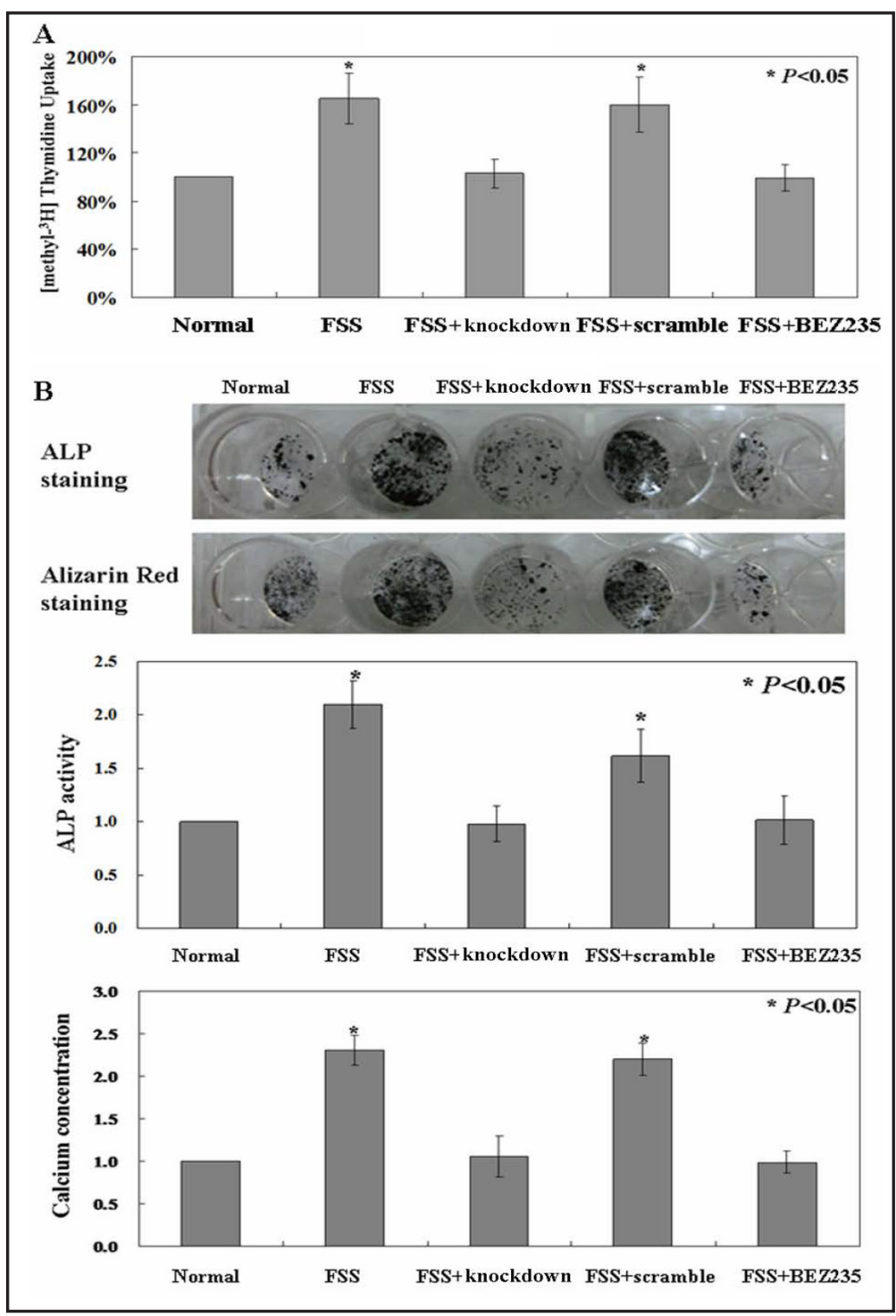

Fig. 5. The expressions of ALP, OPN, OCN, and PON were determined by Western blot. $\beta$-actin expression was used as an internal control.

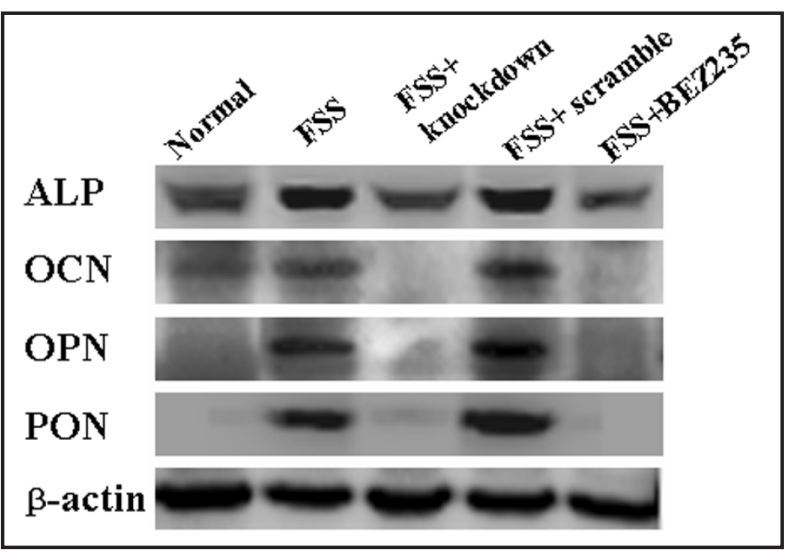

\section{Discussion}

Fluid shear stress (FSS) plays an important role in the proliferation and the differentiation of many cell types. For example, previous studies have shown that pulsatile or oscillatory shear stress can promote smooth muscle cell proliferation [28-30]. Adamo 
Fig. 6. The mechanism of FSS-induced differentiation in PDL cells. Cells were treated as described in Figure 4. Western blot analysis was performed using PI3K and p-PI3K, Akt1 and p-Akt1, mTOR and p- mTOR, and 70S6K and $\mathrm{p}-70 \mathrm{~S} 6 \mathrm{~K}$. $\beta$-actin was used as an internal control.

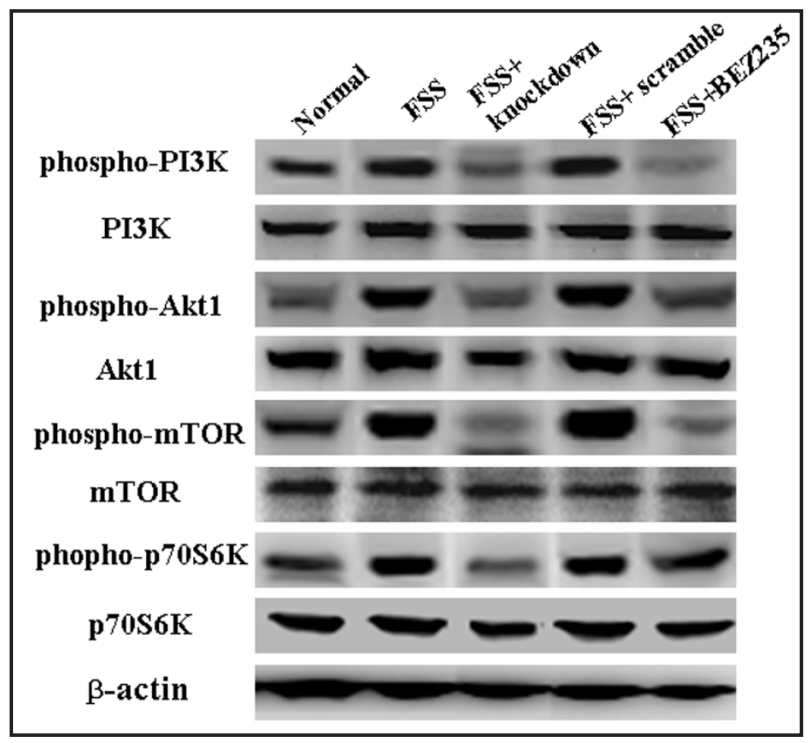

Fig. 7. Up-regulation of microRNA 132 and activation of the mTOR signaling pathway induces osteogenic differentiation in PDL cells. A) Cell proliferation was assessed by [methyl ${ }^{-3} \mathrm{H}$ ] thymidine incorporation assays. B) ALP activity and mineralization were measured by ALP staining and Alizarin Red staining, respectively. Normal: PDL cells; FSS: PDL cells treated with FSS; mir-132 mimic: PDL cells transfected with mir132 mimic; mir-132 scramble: PDL cells transfected with mir-132 scramble; IGF1: PDL cells treated with IGF-1.

et al. [31] showed that under different culture conditions, shear stress can induce hematopoietic differentiation from $\mathrm{Flk}^{+}$ cells. Mechanotransduction is a response of osteoblasts and osteocytes to extracellular FSS stimuli, producing changes in bone metabolism [32]. However, another study has shown that FSS inhibits smooth muscle cell (SMC) proliferation by regulating
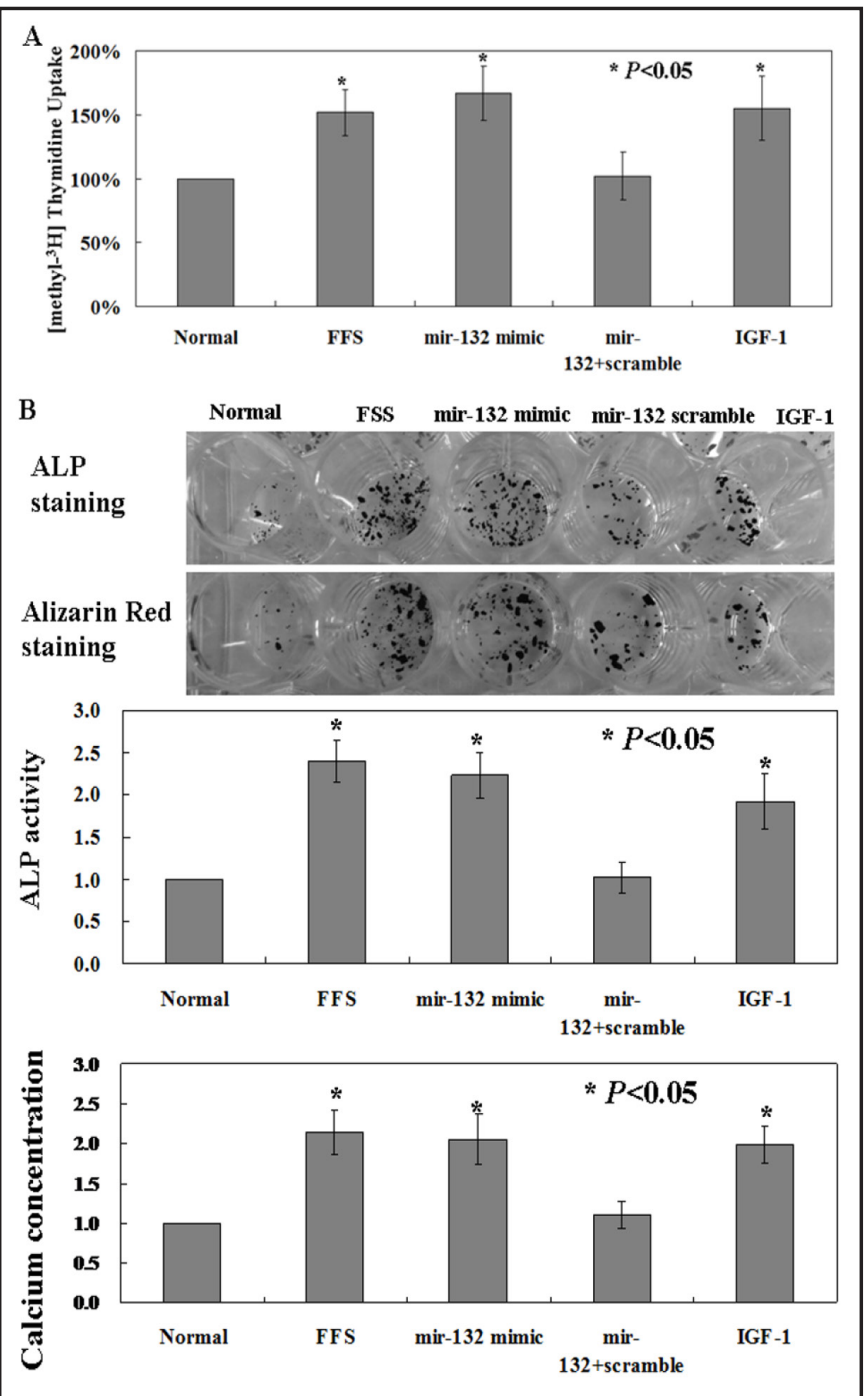

transforming growth factor-beta 1 (TGF- $\beta 1$ ) [33]. To our knowledge, there is no direct evidence in the literature regarding the effects of FSS on PDL cells. 
Fig. 8. The role of mir-132 up-regulation in PDL cells differentiation. Cells were treated as described in Figure 7. Western blot analysis was performed using PI3K and p-PI3K, Akt1 and p-Akt1, mTOR and $\mathrm{p}-\mathrm{mTOR}$, and 70S6K and p-70S6K. $\beta$-actin was used as an internal control.

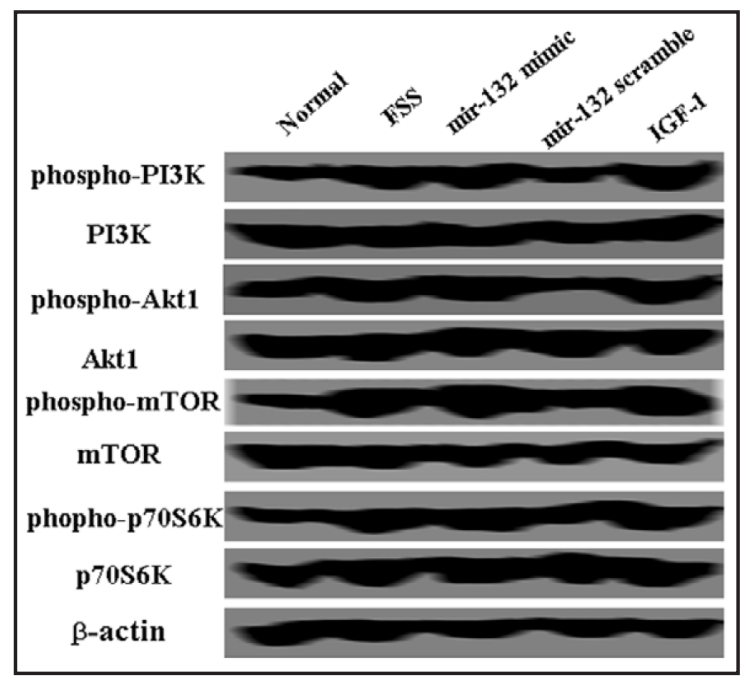

Therefore, the purpose of this study was twofold: (1) to test whether FSS induces proliferation and differentiation of I-PDL cells; and (2) to identify the miRNAs and signaling pathways that translate these mechanical cues into biological responses. We showed that freshly isolated human periodontal ligament (PDL) cells respond to FSS by the mTOR signaling pathway, and that miR-132 is a mediator of FSS-induced proliferation and differentiation in these cells.

Alkaline phosphatase (ALP) is an enzyme produced by osteoblasts that facilitates calcium deposition into the bone matrix [34]. Therefore, ALP activity and calcium deposition are jointly regarded as indicators of osteogenesis. Both factors have been found to be upregulated under FSS stimulation $[35,36]$. Consistent with a previous study using uniform shear stresses, a 30-min steady flow shear stress at 20 dynes/cm2 enhanced ALP activity and calcium deposition [37]. Our results also confirm that ALP activity and calcium deposition in PDL cells can be increased by FSS treatment. Kamata et al. [38] induced ascorbic acid in immortalized PDL cells and observed first an increase in ALP expression, then increases in OPN and OCN expressions. The expression of OPG might also be important to the differentiation of PDL cells [39]. In our studies, we confirmed that these differentiation markers are increased by FSS treatment.

Since microRNAs are known regulators of gene expression and cellular function [40, 41], we listed those miRNAs whose expressions are significantly changed by FSS treatment, as determined using microarray analysis and real-time PCR analysis. The results of this analysis show that miR-132 is three times more prevalent in FSS-treated PDL cells than in untreated cells, suggesting that it plays a specific role in differentiation. Furthermore, miR-132 knockdown counteracts the FSS-induced proliferation and differentiation of PDL cells. Several other lines of evidence support the role of miR-132 in cell differentiation. It is enriched in brain tissue, and in this setting is responsive to neurotrophin signaling, suggesting a prominent role in neuronal morphogenesis, dendritic plasticity, and neuronal differentiation [42-44]. Zhang et al. [45] found that down-regulation of miR-132 by promoter methylation contributes to pancreatic cancer development.

We also explored the signaling pathways associated with miR-132 expression in PDL cells. Vo et al. [46] showed that cAMP-response element binding protein (CREB) could bind to the miR-212/132 locus, and might regulate the transcription of miRNA-132. In addition, the ablation of miR-132 and the loss of CREB activity have similar blocking effects on neuronal function, suggesting that CREB signaling is involved in miR-132 expression [47, 48]. Another study reported that miR-132 mediates the effect of P250GAP on dendritic plasticity [42]. As demonstrated in previous studies, each miRNA can regulate numerous target protein-coding genes, so the full functionality of miRNA can be interpreted as the sum of the functions of the genes it regulates [49]. 
In our study, we found that miR-132 expression could activate the classical mTOR signaling pathway. The mammalian target of rapamycin (mTOR), an evolutionarily conserved serine/threonine protein kinase, integrates both intracellular and extracellular signals and serves as a central regulator of cell metabolism, growth, proliferation, survival, and autophagy [50-52]. The phosphatidylinositol-3 kinase/AKT signaling pathway activates mTOR in turn, directly phosphorylating ribosome protein S6 kinase 1 (S6K1) and eIF4Ebinding protein 1 , both of which are important in controlling the initiation of protein translation $[53,54]$. Consistent with previous studies, we found that the phosphorylated levels of P13K, AKT, mTOR and p70S6K proteins significantly increased in FSS-treated PDL cells. The PDL cells treated with mir-132 knockdown probe or a dual PI3K/mTOR inhibitor, BEZ235 [55], showed no reactions to FSS. These results indicate that miR-132 can activate the mTOR signaling pathway, and that this pathway is critical to the differentiation of PDL cells with FSS treatment.

Collectively, our results confirm that PDL cells differentiate after FSS treatment and that miR-132 expression plays a significant role in this biological process. Furthermore, we provided evidence that miR-132 regulates the differentiation of PDL cells though the mTOR signaling pathway. Unfortunately, we did not investigate the direct targets of miR-132. Activation of the mTOR signaling pathway may be a consequence of the miR-132 regulatory network. PDL cells are crucial for the regeneration of alveolar bone and the dentin surface during the healing of a periodontal wound [27]. Controlling the balance between miR-132 and the mTOR signaling pathway in PDL cells may have potential uses in therapy.

\section{Conflict of Interests}

The authors have declared that no competing interests exist.

\section{Acknowledgments}

We would like to thank Miss Yu Miao for helpful discussions. We also thank Dr. Li Yan for providing the plasmid pBABE-puro-hTERT.

\section{Reference}

1 Nohutcu RM, McCauley LK, Koh AJ, Somerman MJ: Expression of extracellular matrix proteins in human periodontal ligament cells during mineralization in vitro. J Periodontol 1997;68:320-327.

2 McCulloch CA, Bordin S: Role of fibroblast subpopulations in periodontal physiology and pathology. J Periodontal Res 1991; 26:144-154.

- 3 Nyman S, Gottlow J, Karring T, Lindhe J: The regenerative potential of the periodontal ligament. An experimental study in the monkey. J Clin Periodontol 1982; 9:257-265.

4 Nyman S, Lindhe J, Karring T, Rylander H: New attach $\neg$ ment following surgical treatment of human periodontal disease. J Clin Periodontol 1982;9:290-296.

-5 Nojima N, Kobayashi M, Shionome M, Takahashi N, Suda T, Hasegawa K: Fibroblastic cells derived from bovine periodontal ligaments have the phenotypes of osteoblasts. J Periodontal Res 1990;25:179-185.

6 Somerman MJ, Young MF, Foster RA, Moehring JM, Imm G, Sauk JJ: Characteristics of human periodontal ligament cells in vitro. Arch Oral Biol 1990; 35:241-247.

-7 Cho MI, Matsuda N, Lin WL, Moshier A, Ramakrishnan PR: In vitro formation of mineralized nodules by periาodontal ligament cells from the rat. Calcif Tissue Int 1992;50:459-467.

-8 Mukai M, Yoshimine Y, Akamine A, Maeda K: Bone-like nodules formed in vitro by rat periodontal ligament cells. Cell Tissue Res 1993;271:453-460. 


\section{Cellular Physiology Cell Physiol Biochem 2014;33:433-445 and Biochemistry

-9 Weinbaum S, Cowin SC, Zeng Y: A model for the excitation of osteocytes by mechanical loading-induced bone fluid shear stresses. J Biomech 1990;27:339-360.

10 Davies PF: Flow-mediated endothelial mechanotransduction. Physiol Rev 1995;75:519-560.

11 Kreke MR, Huckle WR, Goldstein AS: Fluid flow stimulates expression of osteopontin and bone sialoprotein by bone marrow stromal cells in a temporally dependent manner. Bone 2005;36:1047-1055.

-12 van der Pauw MT, Klein-Nulend J, van den Bos T, Burger EH, Everts V, Beertsen W: Response of periodontal ligament fibroblasts and gingival fibroblasts to pulsating fluid flow: nitric oxide and prostaglandin E2 release and expression of tissue non-specific alkaline phosphatase activity. J Periodontal Res 2000; 35:335343.

13 Maeda A, Soejima K, Bandow K, Kuroe K, Kakimoto K, Miyawaki S, Okamoto A, Matsuguchi T: Force-induced IL-8 from periodontal ligament cells requires IL-1beta. J Dent Res 2007;86:629-634.

14 He L, Hannon GJ: MicroRNAs: small RNAs with a big role in gene regulation. Nat Rev Genet 2004;5:522-531.

15 Ambros V: The evolution of our thinking about microRNAs. Nat Med 2008;14:1036-1040.

16 Pathania M, Torres-Reveron J, Yan L, Kimura T, Lin TV, Gordon V, Teng ZQ, Zhao X, Fulga TA, Van Vactor D, Bordey A: miR-132 enhances dendritic morphogenesis, spine density, synaptic integration, and survival of newborn olfactory bulb neurons. PLoS One 2012;7:e38174.

17 Anand S, Majeti BK, Acevedo LM, Murphy EA, Mukthavaram R, Scheppke L, Huang M, Shields DJ, Lindquist JN, Lapinski PE, King PD, Weis SM, Cheresh DA: MicroRNA-132-mediated loss of p120RasGAP activates the endothelium to facilitate pathological angiogenesis. Nat Med 2010;16:909-914.

18 Somerman MJ, Archer SY, Imm JR, Foster RA: A comparative study of human periodontal ligament cells and gingival fibroblasts in vitro. J Dent Res 1998;67:66-70.

19 Frangos JA, McIntire LV, Eskin SG: Shear stress induced stimulation of mammalian cell metabolism. Biotechnol Bioeng 1998;32:1053-1060.

-20 Gruber R, Kandler B, Fuerst G, Fischer MB, Watzek G: Porcine sinus mucosa holds cells that respond to bone morphogenetic protein (BMP)-6 and BMP-7 with increased osteogenic differentiation in vitro. Clin Oral Implants Res 2004;15:575-580.

21 Haga M, Yamashita A, Paszkowiak J, Sumpio BE, Dardik A: Oscillatory shear stress increases smooth muscle cell proliferation and akt phosphorylation. J Vasc Surg 2003;37:1277-1284.

22 Zahurak M, Parmigiani G, Yu W, Scharpf RB, Berman D, Schaeffer E, Shabbeer S, Cope L: Pre-processing Agilent microarray data. BMC Bioinformatics 2007;8:142.

23 Maira SM, Stauffer F, Brueggen J, Furet P, Schnell C, Fritsch C, Brachmann S, Chène P, De Pover A, Schoemaker K, Fabbro D, Gabriel D, Simonen M,Murphy L, Finan P, Sellers W, García-Echeverría C: Identification and characterization of NVP-BEZ235, a new orally available dual phosphatidylinositol 3-kinase/mammalian target of rapamycin inhibitor with potent in vivo antitumor activity. Mol Cancer Ther 2008; 7:1851-1863.

24 Jayashree Karar, Amit Maity: PI3K/AKT/mTOR Pathway in Angiogenesis. Front Mol Neurosci 2011;4:51.

25 Seo BM, Miura M, Gronthos S, Bartold PM, Batouli S, Brahim J, Young M, Robey PG, Wang CY, Shi S: Investigation of multipotent postnatal stem cells from human eriodontal ligament. Lancet 2004;364:149155.

-26 Fujii S, Maeda H, Wada N, Kano Y, Akamine A: Establishing and characterizing human periodontal ligament fibroblasts immortalized by SV40T-antigen and hTERT gene transfer. Cell Tissue Res 2006;324:117-125.

-27 Shimono M, Ishikawa T, Ishikawa H, Matsuzaki H, Hashimoto S, Muramatsu T, Shima K, Matsuzaka K, Inoue T: Regulatory mechanisms of periodontal regeneration. Microsc Res Tech 2003;60:491-502.

28 Rosati C, Garay R: Flow-dependent stimulation of sodium and cholesterol uptake and cell growth in cultured vascular smooth muscle. J Hypertens 1991;9:1029-1033.

29 Shigematsu K, Yasuhara H, Shigematsu H, Muto T: Direct and indirect effects of pulsatile shear stress on the smooth muscle cell. Int Angiol 2000;19:39-46.

-30 Hung PS, Chen FC, Kuang SH, Kao SY, Lin SC, Chang KW: miR-146a induces differentiation of periodontal ligament cells. J Dent Res 2010;89:252-257.

-31 Adamo L, Naveiras O, Wenzel PL, McKinney-Freeman S, Mack PJ, Gracia-Sancho J, Suchy-Dicey A, Yoshimoto M, Lensch MW, Yoder MC, García-Cardeña G, Daley GQ: Biomechanical forces promote embryonic haematopoiesis. Nature 2009;459:1131-1135.

-32 Turner CH, Pavalko FM: Mechanotransduction and functional response of the skeleton to physical stress: the mechanisms and mechanics of bone adaptation. J Orthop Sci 1998;3:346-355. 


\begin{tabular}{|c|c|c|}
\hline Cellular Physiology & Cell Physiol Biochem 2014;33:433-445 & \\
\hline and Biochemistry & $\begin{array}{l}\text { DOI: } 10.1159 / 000358624 \\
\text { Publisned online: February } 11,2014\end{array}$ & $\begin{array}{l}\text { O 2014 S. Karger AG, Basel } \\
\text { www.karger.com/cpb }\end{array}$ \\
\hline
\end{tabular}

- 33 Ueba H, Kawakami M, Yaginuma T: Shear stress as an inhibitor of vascular smooth muscle cell proliferation. Role of transforming growth factor-beta 1 and tissue-type plasminogen activator. Arterioscler Thromb Vasc Biol 1997;17:1512-1516.

-34 Christenson RH: Biochemical markers of bone metabolism: an overview. Clin Biochem 1997;30:573-593.

-35 Reich KM, Frangos JA: Effect of flow on prostaglandin E2 and inositol trisphosphate levels in osteoblasts. Am J Physiol 1991;261:C428-432.

-36 Nauman EA, Satcher RL, Keaveny TM, Halloran BP, Bikle DD: Osteoblasts respond to pulsatile fluid flow with short-term increases in PGE(2) but no change in mineralization. J Appl Physiol 2001;90:1849-1854.

-37 Kapur S, Baylink DJ, Lau KH: Fluid flow shear stress stimulates human osteoblast proliferation and differentiation through multiple interacting and competing signal transduction pathways. Bone 2003;32:241-251.

- 38 Kamata N, Fujimoto R, Tomonari M, Taki M, Nagayama M, Yasumoto S: Immortalization of human dental papilla, dental pulp, periodontal ligament cells and gingival fibroblasts by telomerase reverse transcriptase. J Oral Pathol Med 2004;33:417-423.

-39 Kanzaki H, Chiba M, Shimizu Y, Mitani H: Dual regulation of osteoclast differentiation by periodontal ligament cells through RANKL stimulation and OPG inhibition. J Dent Res 2001;80:887-891.

40 Bartel DP: MicroRNAs: genomics, biogenesis, mechanism, and function. Cell 2004;116:281-297.

41 Shivdasani RA: MicroRNAs: regulators of gene expression and cell differentiation. Blood 2006;108:36463653.

42 Wayman GA, Davare M, Ando H, Fortin D, Varlamova O, Cheng HY, Marks D, Obrietan K, Soderling TR, Goodman RH, Impey S: An activity-regulated microRNA controls dendritic plasticity by down-regulating p250GAP. Proc Natl Acad Sci U S A 2008;105:9093-9098.

-43 Remenyi J, Hunter CJ, Cole C, Ando H, Impey S, Monk CE, Martin KJ, Barton GJ, Hutvagner G, Arthur JS: Regulation of the miR-212/132 locus by MSK1 and CREB in response to neurotrophins. Biochem J 2010;428:281-291.

44 Magill ST, Cambronne XA, Luikart BW, Lioy DT, Leighton BH, Westbrook GL, Mandel G, Goodman RH: microRNA-132 regulates dendritic growth and arborization of newborn neurons in the adult hippocampus. Proc Natl Acad Sci U S A 2010;107:20382-20387.

45 Zhang S, Hao J, Xie F, Hu X, Liu C, Tong J, Zhou J, Wu J, Shao C: Downregulation of miR-132 by promoter methylation contributes to pancreatic cancer development. Carcinogenesis 2011;32:1183-11189.

-46 Vo N, Klein ME, Varlamova O, Keller DM, Yamamoto T, Goodman RH, Impey S: A cAMP-response element binding protein-induced microRNA regulates neuronal morphogenesis. Proc Natl Acad Sci U S A 2005;102:16426-16431.

47 Olde Loohuis NF, Kos A, Martens GJ, Van Bokhoven H, Nadif Kasri N, Aschrafi A: MicroRNA networks direct neuronal development and plasticity. Cell Mol Life Sci 2012;69:89-102.

-48 Fiore R, Siegel G, Schratt G: MicroRNA function in neuronal development, plasticity and disease. Biochim Biophys Acta 2008;1779:471-478.

49 Sonkoly E, Wei T, Janson PC, Sääf A, Lundeberg L, Tengvall-Linder M, Norstedt G, Alenius H, Homey B, Scheynius A, Ståhle M, Pivarcsi A: MicroRNAs: novel regulators involved in the pathogenesis of psoriasis? PLoS One 2007;2, e610.

-50 Efeyan A, Sabatini DM: mTOR and cancer: many loops in one pathway. Curr Opin Cell Biol 2010;22:169176.

-51 Zoncu R, Efeyan A, Sabatini DM: mTOR: from growth signal integration to cancer, diabetes and ageing. Nat Rev Mol Cell Biol 2011;12:21-35.

-52 Ma XM, Blenis J: Molecular mechanisms of mTOR-mediated translational control. Nat Rev Mol Cell Biol 2009;10:307-318.

-53 She QB, Halilovic E, Ye Q, Zhen W, Shirasawa S, Sasazuki T, Solit DB, Rosen N.: 4E-BP1 is a key effector of the oncogenic activation of the AKT and ERK signaling pathways that integrates their function in tumors. Cancer Cell 2010;18:39-51.

54 Richter JD, Sonenberg N: Regulation of cap-dependent translation by eIF4E inhibitory proteins. Nature 2005;433:477-480.

55 Seitz C, Hugle M, Cristofanon S, Tchoghandjian A, Fulda S: The dual PI3K/mTOR inhibitor NVP-BEZ235 and chloroquine synergize to trigger apoptosis via mitochondrial-lysosomal cross-talk. Int J Cancer 2013;132:2682-2693. 